DOI:10.20396/cel.v60n3.8652079

(cc) $\overline{B Y}-\mathrm{NC}$

\title{
ESTRUTURAS CAUSATIVAS, REFLEXIVAS, RECÍPROCAS E ANTICAUSATIVAS NA LÍNGUA TENETEHÁRA-GUAJAJÁRA (FAMÍLIA TUPÍ-GUARANÍ) ${ }^{1}$
}

\author{
RICARDO CAMPOS CASTRO* \\ QUESLER FAGUNDES CAMARGOS**
}

\begin{abstract}
RESUMO: O objetivo deste artigo é analisar as estruturas causativas, reflexivas, recíprocas e anticausativas na língua Tenetehára (família linguística Tupí-Guaraní). Pretendemos mostrar que esta língua apresenta dois morfemas causativos, a saber: (i) o morfema $\{m u-\}$, que causativiza verbos intransitivos, introduzindo uma causação direta, e (ii) o morfema $\{$-kar\}, cuja função é causativizar verbos transitivos, introduzindo uma causação indireta. Além disso, como será visto, as construções que vêm marcadas por meio do morfema $\{z e-\}$ exibem propriedades de estruturas reflexivas, recíprocas e anticausativas. De forma sucinta, este morfema afixa-se apenas a verbos transitivos, diminuindo sua valência. Adicionalmente, buscaremos investigar as propriedades morfossintáticas e semânticas da coocorrência do prefixo $\{z e-\}$ com os morfemas causativos $\{m u-\}$ e $\{-k a r\}$. Finalmente, verificaremos como se dá o mecanismo de retomada anafórica, a ordem linear em que estes afixos ocorrem, e a semântica relacionada à dinâmica das forças perceptíveis no evento, que é sensível às derivações pertinentes.
\end{abstract}

Palavras-chave: Tupí-Guaraní; Tenetehára; causação; anticausação; reflexivização.

ABSTRACT: The objective of this paper is to analyze the causative, reflexive, reciprocal and anticausatives structures in the Tenetehára language (Tupí-Guaraní family). We intend to show that this language presents two causative morphemes, namely: (i) morpheme $\{m u-\}$, which causativize intransitive verbs, introducing direct causation; and (ii) the morpheme $\{-k a r\}$ whose function

${ }^{1}$ Gostaríamos de registrar nossos agradecimentos a dois pareceristas anônimos do Caderno de Estudos Linguísticos da UNICAMP, cujos comentários contribuíram para o aperfeiçoamento deste artigo. Agradecemos ainda à audiência do XVII Congresso da Associação de Linguística e Filologia da América Latina - ALFAL (João Pessoa, Paraíba, 2013), evento em que esse trabalho foi inicialmente apresentado. Esta investigação foi desenvolvida durante trabalho a campo realizado na Terra Indígena Araribóia (nas aldeias Lagoa Quieta, Juçaral, Barreirinha e Zutiwa) e na Terra Indígena Bacurizinho (na aldeia Bacurizinho) entre os anos 2010 e 2018. Gostaríamos de agradecer o importante apoio do povo indígena Tenetehára, sem o qual não seria possível realizar a pesquisa aqui apresentada; em especial à Cíntia Maria Santana da Silva Guajajára, Pedro Paulino Guajajára e Raimundo Alves de Lima Guajajára. Os erros e as inconsistências que persistem são de nossa inteira responsabilidade.

* Professor visitante (pós-doutorado) no Departamento de Linguística da Universidade da Geórgia (UGA, EUA) e no Instituto de Estudos da Linguagem (IEL) da Universidade Estadual de Campinas (UNICAMP, Brasil). Esta pesquisa conta com o apoio financeiro da Fundação de Amparo à Pesquisa do Estado de São Paulo (FAPESP). Processos 2017/09615-9 (Brasil) e 2018/06203-4 (EUA), respectivamente. ricardorrico@uol.com.br.

${ }^{* *}$ Professor do Departamento de Educação Intercultural da Universidade Federal de Rondônia (DEINTER/UNIR). Membro do Grupo de Pesquisa em Educação na Amazônia (GPEA) e do Laboratório de Línguas e Culturas Indígenas (LALIC/UNIR). queslerc@gmail.com. 
is to causativize transitive verbs, introducing an indirect causation. Moreover, as will be seen, the constructions that are marked by the morpheme $\{z e-\}$ exhibit properties of reflexive, reciprocal and anticausative structures. Briefly, this morpheme appears only to transitive verbs, decreasing its valence. In addition, we will seek to investigate the morphosyntactic and semantic properties of the cooccurrence of the prefix $\{z e-\}$ with the causative morphemes $\{m u-\}$ and $\{-k a r\}$. Finally, we will verify how the anaphoric resumption mechanism is given, the linear order in which these affixes occur and the semantics related to the dynamics of the perceivable forces in the event is sensitive to the relevant derivations.

Keywords: Tupí-Guaraní; Tenetehára; causation; anticausation; reflexivization.

\section{INTRODUÇÃO}

Este artigo tem por objetivo oferecer uma análise descritiva das estruturas causativas, reflexivas, recíprocas e anticausativas na língua Tenetehára (família linguística Tupí-Guaraní). Os dados linguísticos que subsidiam a presente investigação foram coletados no período de 2010 a 2018, nas aldeias Lagoa Quieta, Barreirinha, Juçaral e Zutiwa, da Terra Indígena Araribóia, localizadas nos municípios de Amarante e Arame, do Estado do Maranhão; bem como na Aldeia Bacurizinho, da Terra Indígena Bacurizinho, situada no município de Grajaú, Estado do Maranhão. Os dados linguísticos apresentados neste artigo foram cedidos por professores indígenas falantes bilíngues (Guajajára-Português). Todo material foi registrado e transcrito, utilizando-se a ortografia adotada pelas comunidades indígenas Guajajára, e compreende listas de palavras e sentenças (nominais e verbais) elicitadas. Realizamos ainda gravações de relatos orais, tais como mitos e histórias reais, os quais foram posteriormente transcritos e analisados junto com os professores indígenas. Ademais, foram considerados ainda subsidiariamente os seguintes trabalhos a respeito da língua Tenetehára, a saber: Boudin (1966), Bendor-Samuel (1972), Harrison (1995), Duarte (1997, 2003, 2005, 2007), Carvalho (2001), Castro (2007, 2017), Silva (2010), Camargos (2013, 2017ab) e Camargos e Castro (2013, 2015).

Em termos descritivos, mostraremos que esta língua apresenta dois morfemas causativos, a saber: (i) o morfema $\{m u$ - $\}$, que causativiza verbos intransitivos ativos e inativos ${ }^{2}$, introduzindo uma causação direta, e (ii) o morfema $\{-k a r\}$, cuja função é causativizar verbos transitivos, introduzindo uma causação indireta.

${ }^{2}$ No âmbito dos estudos descritivos das línguas indígenas da família linguística Tupí-guaraní, os verbos intransitivos ativos correspondem a verbos de ação e de movimento; por exemplo: ata "andar", apyk "sentar", zàn “correr”, por "pular", 'ar "cair”, mano "morrer”, entre muitos outros. Note que estes verbos são denominados na literatura gerativa como verbos inergativos e inacusativos (pode-se afirmar, no entanto, que não há em Tenetehára, aparentemente, uma distinção formal entre estas duas classes verbais). Os verbos intransitivos inativos, por sua vez, referem-se a verbos que indicam estado, os quais em português são comumente classificados como adjetivos. São eles: aku "quente", katu "bom", puràg "bonito" etc. A diferenciação formal entre intransitivos ativos e inativos se evidencia por meio dos paradigmas de concordância os quais são acionados por cada verbo. Dessa forma, os verbos intransitivos ativos acionam os prefixos de concordância do sistema nominativo, ao passo que os verbos intransitivos inativos engatilham os prefixos tradicionalmente chamados de relacionais. Para mais detalhes, convidamos os leitores a consultar os trabalhos de Duarte (1997, 2003, 2007, 2017). 
Além desses morfemas, investigaremos ainda a natureza gramatical do morfema $\{z e-\}$, responsável pelas vozes reflexiva, recíproca e anticausativa.

A partir da análise detalhada de cada um desses morfemas, analisaremos estruturas morfologicamente complexas, em que há a coocorrência dessas três unidades gramaticais, conforme os exemplos em (1) abaixo ${ }^{3}$ :

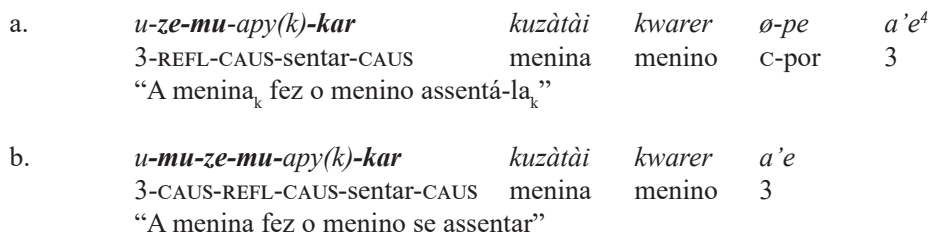

Antes de começar, é importante ressaltar que o fenômeno de coocorrência de morfemas causativos e reflexivos já foi investigado em várias línguas da família Tupí-Guaraní (RODRIGUES, 1953; LEMOS BARBOSA, 1956; LEITE, 1994; SEKI, 2000; entre muitos outros). Por ter sido a obra que motivou a elaboração do presente artigo, apresentamos abaixo os dados do Tupi Antigo, retirados de Lemos Barbosa (1956, p. 191), nos quais é exibida a coocorrência de dois morfemas causativos $\{m o-\}$ e do reflexivo $\{\hat{\imath} e-\}$.

\begin{tabular}{|c|c|}
\hline Tupi Antigo & \\
\hline$a k u b$ & "ser quente" \\
\hline$a-\hat{\imath}-\mathbf{m o}-a k u b$ & "esquento-o" \\
\hline$a-\hat{\boldsymbol{\imath}} \boldsymbol{e}-\boldsymbol{m o}-a k u b$ & "esquento-me" \\
\hline$a-\hat{\imath}-\mathbf{m o} \boldsymbol{-} \hat{\boldsymbol{\imath}} \boldsymbol{e}-\boldsymbol{m o}-a k u b$ & "faço-o esquentar-se" \\
\hline
\end{tabular}

Nos exemplos em (2) acima, o predicado descritivo $a k u b$ "ser quente" recebe o morfema causativo $\{m o-\}$, evolvendo a $a-\hat{l}-m o-a k u b$ "esquento-o", um verbo transitivo. Nesta situação, emerge também o morfema $\{\hat{\imath}-\}$, que de acordo com o autor trata-se de um elemento eufônico ${ }^{5}$. A seguir, é afixado o morfema $\{\hat{\imath} e-\}, o$

${ }^{3}$ Abreviaturas utilizadas neste trabalho: 1: primeira pessoa; 2: segunda pessoa; 3: terceira pessoa; AC: anticausativo; C: prefixo de continuidade; CAUS: causativo; COMP: complementizador; G: modo gerúndio; ITER: aspecto iterativo; N: neutro; PL: plural; REC: recíproco; REFL: reflexivo; REL: prefixo relacional; sG: singular.

${ }^{4}$ No final das orações em Tenetehára ocorre uma série de partículas que instanciam os traços de pessoa do sujeito da predicação. No dado em (3a), por exemplo, a partícula a'e instancia os traços de $3^{a}$ pessoa do singular do DP sujeito kwarer "menino". Podem ocorrer ainda as seguintes partículas: ihe: 1SG, ure: 1EXCL, zane: 1INCL, ne: 2SG, pe: 2PL, a'e: 3SG, a’e wà: 3PL. Para mais detalhes, direcionamos o leitor ao trabalho de Camargos (2017b).

${ }^{5}$ Este mesmo prefixo também ocorre na língua Avá Guarani (e possivelmente em outras línguas do tronco Tupí), como pode ser visto no exemplo abaixo retirado de Freitas (2011, p. 161):
(i) che po-i-nupã
1s 1s/2PL-REL-bater
"Eu vos bato"

Freitas (2011), no entanto, analisa este morfema como prefixo relacional e não como elemento eufônico. Em Guarani-Mbyá, por sua vez, há também um prefixo \{i- $\}$, o qual se realiza nessa mesma posição, conforme exemplo de Martins (2003, p. 53) abaixo:

(ii) $a$-j-apo

tembi'u 
qual tem a função de reflexivizar o predicado, tornando-o $a$-îe-mo-akub "esquentome". Note ainda que, ao receber o morfema reflexivo, o impacto do evento passa a recair sobre o próprio sujeito da sentença. Finalmente, outro morfema causativo $\{m o-\}$ é unido à estrutura, resultando em um predicado duplamente causativizado $a-\hat{\imath}-m o-\hat{\imath} e-m o-a k u b$ "faço-o esquentar-se". Assim, o agente da sentença agora atua sobre um argumento agente-afetado, fazendo-o realizar uma ação sobre si próprio.

O artigo está organizado em 6 seções. Nesta seção, apresentamos os objetivos deste trabalho. Na seção 2, averiguaremos como se dá o processo de causativização em Tenetehára. Na seção 3, investigaremos a causativização direta e indireta, de acordo com Camargos (2013). Na seção 4, analisaremos o escopo do morfema $\{z e-\}$, procurando evidenciar que tal unidade gramatical cobre as funções de reflexivo, recíproco e anticausativo. Na seção 5, o objetivo será examinar as propriedades morfossintáticas e semânticas dos morfemas causativos e reflexivo em contexto de coocorrência. Finalmente, na seção 6, apresentaremos nossas considerações finais.

\section{PROCESSO DE CAUSATIVIZAÇÃO EM TENETEHÁRA}

Em termos descritivos, há dois morfemas causativos em Tenetehára, a saber: o prefixo $\{m u$ - $\}$ e o sufixo $\{-k a r\}$. O morfema causativo $\{m u-\}$, de acordo com Castro (2007), junta-se a verbos intransitivos, a fim de transformá-los em verbos transitivos causativos, conforme é possível verificar a partir dos seguintes exemplos.

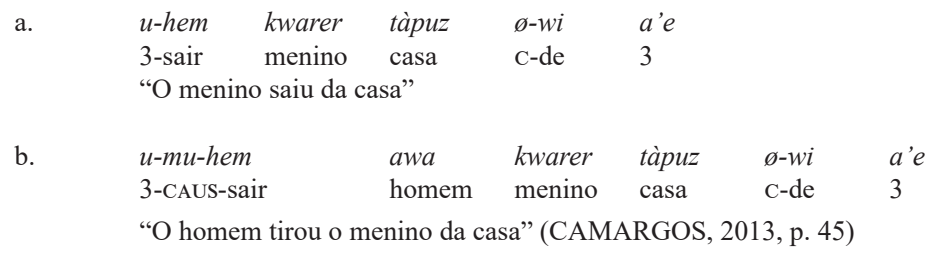

Em (3a), o verbo hem "sair" seleciona um único argumento nuclear, o DP kwarer "menino". Em (3b), por sua vez, a predicação monovalente é causativizada por meio do morfema $\{m u$ - $\}$. Assim, o predicado $m u$-hem "fazer sair" passa a exibir comportamento sintático transitivo, porque projeta dois argumentos nucleares: o DP objeto kwarer "menino" e o DP sujeito awa "homem" com a função temática de agente. Comparem-se, a seguir, os exemplos em que ocorre a causativização do verbo "banhar":

\footnotetext{
1SG-3REL-fazer comida

"faço comida"
}

De acordo com Martins (2003), o prefixo \{i- $\}$, em Guarani-Mbyá, tem a função de marcar o participante objeto de verbos transitivos, por meio dos prefixos relacionais. Agradecemos a um dos pareceristas anônimos que nos apontou sobre a possibilidade de outras análises para este prefixo. 
(4)

a. u-zahak kwarer a'e
3-banhar menino 3
"O menino banhou"

b.

u-mu-zahak kuzà $\quad \begin{aligned} & \text { kwarer } \\ & \text { 3-CAUS-banhar }\end{aligned}$ mulher menino 3
"A mulher banhou o menino" (CAMARGOS, 2013, p. 146)

No dado (4a), o predicado intransitivo zahak "banhar" seleciona o DP sujeito kwarer "menino". Já no exemplo (4b), o morfema causativo $\{m u-\}$ é afixado ao verbo zahak "banhar", tornando-o transitivo. Isso pode ser observado porque em (4b) existe um argumento adicional, a saber: o DP sujeito kuzà "mulher", cuja propriedade semântica é a de agente. Note ainda que o DP kwarer "menino" em (4a) tem a propriedade semântica de agente. No entanto, em (4b), este argumento passa a exercer a função semântica de afetado.

O morfema causativo $\{-k a r\}$, por sua vez, causativiza predicados transitivos. O resultado desse processo de aumento de valência é um predicado verbal que apresenta três argumentos nucleares, conforme o exemplo abaixo:

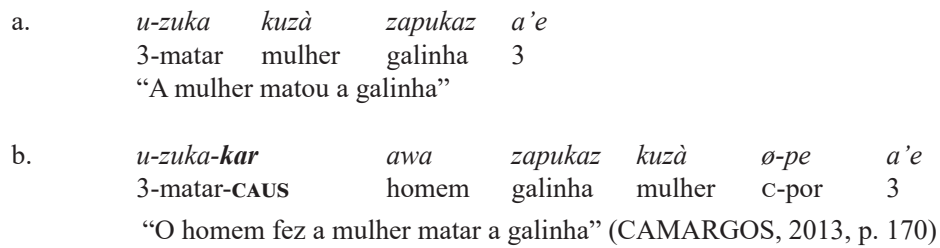

No exemplo (5a), há o verbo transitivo zuka "matar", o qual c-seleciona dois DPs, o sujeito kuzà "mulher" e o objeto zapukaz "galinha". Já em (5b), ocorre um processo de aumento de valência verbal, o qual pode ser descrito da seguinte maneira: o morfema $\{-k a r\}$ é afixado ao predicado zuka "matar", sendo realizado como zuka-kar "fazer matar". Com o acréscimo do sufixo causativo $\{-k a r\}, o$ predicado passa a selecionar três argumentos: um sujeito agente, um objeto tema e um objeto oblíquo agente-afetado. Note que o sujeito kuzà "mulher", da oração matriz, recebe a posposição pe e tem sua função temática mudada de agente para agente-afetado. No âmbito da tipologia linguística, este agente causado equivale ao causee (causado), conforme se observa, por exemplo, em Comrie (1981). Finalmente, o objeto da oração inicial mantém inalterados tanto sua função sintática quanto seu papel temático.

Vale ressaltar que a atribuição do papel temático de agente-afetado ao argumento causee, kuzà "mulher", do predicado causativizado, pode ser explicada porque tal argumento, de acordo com Comrie (1981), retém menor grau de controle na estrutura em relação a um agente prototípico. Tal assunção assegura que há apenas um argumento com o papel temático de agente, o que, por sua vez, obedece ao que estipula a Teoria de Papéis Temáticos.

Em conformidade com Camargos (2013, 2017a), podemos notar que é possível a coocorrência dos morfemas $\{m u-\}$ e $\{-k a r\}$. Para que isso ocorra, é 
necessário que um verbo intransitivo seja inicialmente causativizado pelo morfema $\{m u-\}$ e posteriormente causativizado por meio do sufixo causativo $\{-k a r\}$, de acordo os exemplos abaixo:

(6)

a.

$\begin{array}{llllll}\text { u-mu-hem } & \text { awa } & \text { kwarer } & \text { tàpuz } & \varnothing \text {-wi } & a^{\prime} \text { ' } \\ \text { 3-CAUS-sair } & \text { homem } & \text { menino } & \text { casa } & \text { C-de } & 3 \\ \text { "O homem tirou o menino da casa" } & & & \end{array}$

b.

u-mu-hem-kar kuzà kwarer awa ø-pe tàpuz $ø$-wi a'e
3-CAUS-sair-CAUS mulher menino homem $\quad$ C-por casa
"A mulher fez o menino sair da casa por meio do homem" ou
"A mulher fez o homem tirar o menino da casa"

(7)
a.
$\begin{array}{llll}\text { u-mu-zahak } & \text { kuzà } & \text { kwarer } & a^{\prime} e \\ \text { 3-CAus-banhar } & \text { mulher } & \text { menino } & 3\end{array}$
"A mulher banhou o menino"
b.

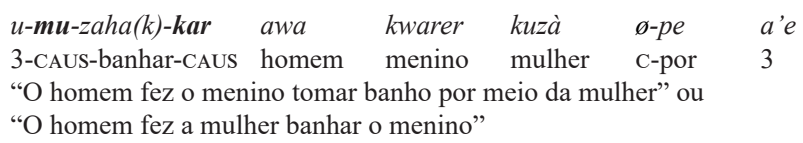

Nos exemplos acima, os verbos intransitivos recebem, primeiramente, o morfema $\{m u-\}$, derivando as formas transitivas $m u$-hem "tirar" e $m u$-zahak "banhar", respectivamente. Em seguida, o sufixo causativo $\{-k a r\}$ é afixado aos predicados mu-hem "tirar" e mu-zahak "banhar", derivando os complexos morfológicos mu-hem-kar "fazer tirar" e mu-zaha(k)-kar "fazer banhar". Em suma, a descrição apresentada até aqui mostra que verbos intransitivos e transitivos podem sofrer alteração de valência, quando se juntam aos afixos causativos $\{m u-\}$ e $\{-k a r\}$. A próxima seção tem por objetivo a análise de dois tipos semânticos de causação, a saber: a causação direta e a indireta.

\section{CAUSAÇÃO DIRETA E INDIRETA}

Como foi visto na seção anterior, os morfemas causativos, no que se refere à morfossintaxe, distinguem-se entre si quanto ao fato de, por um lado, o morfema $\{m u-\}$ causativizar apenas verbos intransitivos e, por outro, o morfema $\{-k a r\}$ causativizar somente predicados transitivos. Nesta seção, mostraremos, a partir dos trabalhos de Camargos (2013, 2017a), que estes dois morfemas também se diferem quanto ao tipo semântico de causação que cada um introduz ao evento.

De acordo com Whaley (1997), a distinção básica entre a causação direta e a causação indireta refere-se à capacidade da mente humana em descrever a relação entre dois eventos. Como os dois rótulos já indicam, a causação direta refere-se a uma situação em que as ações de um causador têm impacto imediato sobre as ações do participante causado, ao passo que a causação indireta referese à situação em que a causação é mais distante. Para sermos mais precisos, veja 
a seguir como Whaley (1997, p. 194) formula a distinção entre os dois tipos de causações:

Por exemplo, você está sentado em um banco em um cruzamento movimentado e têm a infelicidade de presenciar um terrível acidente. Uma menina pequena persegue uma bola de basquete que ela estava driblando na rua depois que a bola se deslocou do seu pé. Nesse exato instante, um carro em alta velocidade vira a esquina e atinge a menina. É muito mais provável que você grite: "Eu acho que ele a matou" ao invés de "Eu acho que ele fez com que ela morresse". Se ambas as declarações são causativas, por que a primeira seria tão obviamente preferida? A construção analítica causativa fazer morrer implica uma causação indireta. Mas nesse cenário não há duvidas de que a ação do motorista levou diretamente à morte da menina, independentemente de ele ter ou não a intenção de fazê-lo. Portanto, a expressão fazer morrer é enganosa. Ela falha a capturar a natureza da causação ${ }^{6}$ (WHALEY, 1997, p. 194).

Para Camargos (2013, 2017a), acompanhando a intuição de Whaley (1997), a causação na língua Tenetehára pode ser direta ou indireta ${ }^{7}$. $\mathrm{O}$ autor afirma que a língua Tenetehára utiliza o prefixo causativo $\{m u-\}$, como em (8b), para indicar a causação direta e emprega o sufixo causativo $\{-k a r\}$, como em (8c), para denotar a causação indireta.

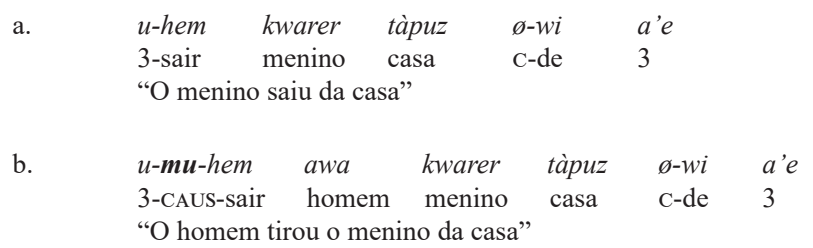

6 "For example, you are sitting on a bench at a busy intersection and have the misfortune of witnessing a terrible accident. A small girl chases a basketball that she has been dribbling into the street after it caroms off her foot. At just the moment, a speed car zips around the corner striking the girl. It is far more likely that you yell out 'I think he killed her' than 'I think he caused her to die'. If both the utterances are causatives, why would one be so obviously preferred? The analytical causative construction cause to die implies indirect causation, but in this scenario there is no doubt that the driver's actions directly brought about the girl's death, even if there was no intention to do so. Therefore, to use cause to die is misleading. It fails to capture the nature of the causation" (WHALEY, 1997, p. 194).

${ }^{7}$ Leite (1994) já havia mostrado na língua Tapirapé (Tupí-Guaraní) a distinção entre uma causativização que envolve (i) o morfema $\{m a-\}$ e (ii) os morfemas $\{m a-\}$ e $\{$-akãt $\}$ simultaneamente. Segundo a autora, no primeiro caso, o agente está diretamente envolvido na ação expressa pelo verbo, enquanto que no segundo caso, o agente está envolvido indiretamente. Vejamos os exemplos retirados de Leite (1994, p. 76):

(i) $\tilde{a}-m a-x e^{\prime} \tilde{e g}$

1sG-CAUS-falar

"Eu o fiz falar"

(ii) $\tilde{a}-m a-x e$ 'ẽg-akãt

1sG-CAUS-falar-CAus

"Eu fiz com que ele falasse"

A respeito desses exemplos, Leite (1994, p. 123) afirma que "há diferenças no significado de construções causativas com raízes intransitivas, quando apenas $m a$ - é prefixado à raiz verbal ou quando $m a-$ e $a k a ̃ t$ são fixados. No primeiro caso, o agente está diretamente envolvido na ação expressa pelo verbo e, no segundo, sua participação é indireta". 


$\begin{array}{llllcc}\text { c. } & \text { u-mu-hem-kar } & \text { awa } & \text { kwarer tàpuz } & \varnothing \text {-wi } & \text { 'e } \\ \text { 3-CAUS-Sair-CAUS } & \text { homem menino casa } & \text { C-de } & 3 \\ \text { "O homem fez o menino sair da casa" (CAMARGOS, 2013, p. 45-46) }\end{array}$

Observe que o morfema causativo $\{m u$ - $\}$ é utilizado para indicar a causação direta, conforme o exemplo (8b). A causação indireta, por sua vez, é marcada pela dupla causativização quando o predicado básico for intransitivo. Considere a seguinte situação hipotética em (8b): uma casa está pegando fogo e um menino se encontra desmaiado dentro deste ambiente, por causa da fumaça que inalou. Assim, um homem adentra a casa e retira o menino. Desta forma, o menino recebe um impacto direto da ação do causador. Já em (8c), a situação imaginada pode ser: um homem deseja que o menino se retire da casa. Neste caso, ele encara o menino fazendo-o entender que deve sair. Logo, o menino não recebe diretamente o impacto da ação do causador. Isso porque não é exatamente o homem que retira o menino da casa, mas ele cria uma circunstância que provoca a saída do menino. A interpretação de causação indireta no exemplo (8c) pode ser reforçada pelo exemplo (8d) abaixo, em que a causação desencadeada pelo sujeito awa "o homem" é indireta, uma vez que "o homem (indiretamente) faz o menino sair da casa" e (ii) a causação direta é executada pelo argumento posposicionado kuzà "mulher".

d. u-mu-hem-kar awa kwarer kuzà ø-pe tàpuz
3-CAus-wi a'e
"O homem fez o menino sair da casa por meio da mulher" ou
"O homem fez a mulher tirar o menino da casa"

Com o objetivo de esclarecer melhor essa distinção entre causação direta e indireta, apresentamos mais um exemplo a seguir.
a. w-ata kwarer a'e
3-andar menino 3
"O menino andou"
b. u-mu-ata awa kwarer a'e
3-CAUS-andar homem menino 3
"O homem andou o menino" (em um contexto no qual o homem segura a mão do menino, ensinando-o a andar)
c. u-mu-ata-kar awa kwarer a'e
3-CAUS-andar-CAUS homem menino 3
"O homem fez o menino andar" (CAMARGOS, 2013, p. 146)
d. u-mu-ata-kar awa kwarer kuzà ø-pe a'e
3-CAUS-andar-CAus homem menino mulher c-por 3
"O homem fez o menino andar por meio da mulher" ou
"O homem fez a mulher andar o menino" (no contexto em que a mulher segura a mão do menino, ensinando-o a andar)

Ao se comparar os exemplos acima, pode-se perceber que em (9b) emerge a causação direta, enquanto em (9c) surge a causação indireta. Destarte, podemos 
conceber os seguintes cenários: para (9b), um homem, ensinando o menino a andar, dá a mão para ele, fazendo-o andar. Para (9c), o menino está muito cansado e não quer caminhar. Porém, o homem dá uma ordem enérgica para que o menino ande. Pode-se afirmar que, neste último exemplo, no entanto, o participante causado não recebe diretamente o impacto da ação do causador, já que estamos diante da causativa indireta. A interpretação de causação indireta de (9c) é reforçada pelo exemplo (9d), tendo em vista a causação desencadeada pelo sujeito awa "o homem" ser indireta, uma vez que "o homem indiretamente faz o menino andar", ao passo que a causação direta é executada pelo argumento posposicionado kuzà "mulher".

De acordo com Camargos (2013, 2017a), devido ao fato de o morfema $\{m u-\}$ ter a capacidade de produzir apenas a causação direta, alguns verbos intransitivos não podem ser causativizados por meio deste morfema, conforme os exemplos a seguir:
a.
$\begin{array}{lll}\text { u-puka } & \text { kwarer } & \text { a'e } \\ \text { 3-rir } & \text { menino } & 3\end{array}$
"O menino riu"
b.
*u-mu-puka
3-CAUS-rir
kuzà kwarer a'e
"A mulher fez o menino rir" (CAMARGOS, 2013, p. 42)
c.

$\begin{array}{llll}\text { u-mu-puka-kar } & \text { kuzà } & \text { kwarer } & a^{\prime} \text { e } \\ \text { 3-CAUS-rir-CAUS } & \text { mulher menino } 3 & 3 \\ \text { "A mulher fez o menino rir" (CAMARGOS, 2013, p. 43) }\end{array}$
a. i-azu pako a'e
3-maduro banana 3
"A banana está madura"
b. *u-mu-azuawa pako a'e
3-CAUS-maduro homem banana 3
"O homem amadureceu a banana" (CAMARGOS, 2013, p. 43)
$\begin{array}{lll}\text { c. } & \text { awu-azu-kar a } \text { a } \\ \text { 3-CAUS-maduro-CAUS homem banana } & \text { a'e }\end{array}$
"O homem fez a banana amadurecer" (CAMARGOS, 2013, p. 50)

(11)

Os exemplos (10b) e (11b) são agramaticais devido ao fato de os eventos descritos pelos predicados causados não permitirem que sejam diretamente causados. Na verdade, os eventos indicados pelos verbos puka "rir" e azu "estar maduro" só aceitam uma causação indireta, como indicam as sentenças (10c) e (11c). Uma outra forma de explicar a agramaticalidade dos exemplos em (b), é considerar que os eventos descritos pelos predicados em (a) são internamente causados, por isso "não podem ser externamente causados" (cf. SMITH, 1970, p. 107). Logo, parece haver um mapeamento biunívoco da seguinte forma: verbos que são externamente causados aceitam uma causação direta, ao passo que verbos 
que são internamente causados identificam-se apenas com uma causação indireta. A seguir, apresentamos as funções desempenhadas pelo mofema $\{z e-\}$.

\section{O MORFEMA $\{Z E-\}$ E SUAS FUNÇÕES}

Nesta seção, o objetivo é investigar a instanciação de três tipos de vozes realizadas pelo morfema $\{z e-\}$, a saber: reflexiva, recíproca e anticausativa, nos termos de Castro (2017). Comecemos, então, pela voz reflexiva.

\subsection{Voz Reflexiva}

Em termos descritivos, o prefixo $\{z e-\}$, conforme Castro $(2007,2017)$, afixase a verbos transitivos, resultando na diminuição de valência verbal. É possível observar que a presença desse reflexivo denota que o sujeito pratica e recebe a ação indicada pelo verbo, conforme demonstram os exemplos a seguir:

\begin{tabular}{|c|c|c|c|c|c|c|c|}
\hline a. & $\begin{array}{ll}\text { u-mim } & \text { awa } \\
\text { 3-esconder } & \text { homem }\end{array}$ & $\begin{array}{l}a^{\prime} e \\
\text { aquele }\end{array}$ & $\begin{array}{l}\text { temetarer } \\
\text { dinheiro }\end{array}$ & $\begin{array}{l}\text { tapuz } \\
\text { casa }\end{array}$ & $\begin{array}{l}\text { ø-pupe } \\
\text { c-em }\end{array}$ & $\begin{array}{l}a^{\prime} e \\
3\end{array}$ & $\begin{array}{l}w a ̀ ~ \\
\mathrm{PL}\end{array}$ \\
\hline & "Os homens escondera & $\mathrm{m}$ aquele & dinheiro na & casa" & & & \\
\hline b & u-ze-mim & $a w a$ & tapuz & ø-рире & $a^{\prime} e$ & & $w a ̀$ \\
\hline & 3-REFL-esconder & homem & casa & C-em & 3 & & PL \\
\hline
\end{tabular}

No exemplo em (12a), ocorre o verbo transitivo mim “esconder" que seleciona dois DPs, o sujeito awa "homem" e o objeto a'e temetarer "aquele dinheiro". Já no exemplo em (12b), o morfema $\{z e-\}$ é afixado ao verbo mim "esconder", fazendo emergir uma estrutura reflexiva. Devido a isso, o sujeito se torna o agente de uma ação que recai sobre ele próprio. Considere também os seguintes exemplos.
a.

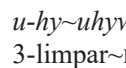
awa h-uwa pàn ø-pupe a'e
"O homem limpou o rosto de alguém com um pano" (CASTRO, 2007, p. 26)
b.

$\begin{array}{llll}\text { u-ze-hy zehyw awa pàn } & \text { ø-pupe } & \text { a'e } \\ \text { 3-REFL-limpar } \sim \text { ITER homem pano } & \text { C-com } & 3 \\ \text { "O homem se limpou com um pano" } & & \end{array}$

Em (13) ocorre um processo análogo ao de (12); o verbo transitivo hyw "limpar", em (13a), seleciona dois DPs, o sujeito awa "homem" e o objeto huwa "o rosto de alguém". No exemplo em (13b), o morfema reflexivo \{ze-\} é prefixado ao verbo hyw "limpar", fazendo emergir uma estrutura reflexiva, já que o sujeito pratica e sofre a ação descrita pelo verbo. Na próxima subseção, apresentamos considerações acerca da voz recíproca. 


\subsection{Voz Recíproca}

Além dos contextos arrolados na seção anterior, outros dados mostram que a unidade gramatical $\{z e-\}$, além de ser um reflexivo, pode ser um elemento anafórico da classe dos recíprocos. No âmbito da Gramática Gerativa, a estreita relação entre reflexivos e recíprocos é apontada por Chomsky (1995, p. 95) com a seguinte afirmação:

As anáforas, que incluem os recíprocos e reflexivos, exigem antecedentes que os vinculem. Neste aspecto, o seu comportamento é bastante diferente dos pronomes, os quais podem ter antecedentes que os vinculem, mas não necessitam tê-los. Além disso, pelo menos em inglês e em algumas outras línguas, o antecedente de uma anáfora tem de ser local em relação à anáfora. Em particular, nós temos [...] a Condição $A$ da teoria da ligação, [a saber:] as anáforas devem ser vinculadas em um certo domínio de vinculação ${ }^{8}$ (CHOMSKY, 1995, p. 95).

Nessa linha de investigação, assumiremos, doravante, que o prefixo $\{z e-\}$, em Tenetehára, além de codificar a função reflexiva, possui ainda a propriedade de indicar a voz recíproca, como nos dados de (14) a (16).

\begin{tabular}{|c|c|c|c|c|}
\hline $\begin{array}{l}\text { u-ze-(e)xak } \\
\text { 3-REC-ver }\end{array}$ & $\begin{array}{l}\text { kuzà } \\
\text { mulher }\end{array}$ & $\begin{array}{l}\text { tekohaw } \\
\text { aldeia }\end{array}$ & $\begin{array}{l}r \text {-upi } \\
\text { C-em }\end{array}$ & $\begin{array}{l}a^{\prime} e \\
3\end{array}$ \\
\hline \multicolumn{5}{|c|}{ "As mulheres viram umas às outras na aldeia" } \\
\hline $\begin{array}{l}u-z(e) \text {-àwàxi } \\
\text { 3-REC-encontrar } \\
\text { "Os homens }\end{array}$ & $\begin{array}{l}\text { awa } \\
\text { homem }\end{array}$ & $\begin{array}{l}\text { yrykaw } \\
\text { rio } \\
\text { outros no }\end{array}$ & $\begin{array}{l}\text { ø-pe } \\
\text { c-em }\end{array}$ & $\begin{array}{l}a^{\prime} e \\
3\end{array}$ \\
\hline $\begin{array}{l}\text { u-ze-zuwàn } \\
\text { 3-REC-abraçar } \\
\text { "O }\end{array}$ & $\begin{array}{l}\text { kwarer } \\
\text { menino }\end{array}$ & $\begin{array}{l}a^{\prime} e \\
3\end{array}$ & $\begin{array}{l}w \grave{a} \\
\text { PL }\end{array}$ & \\
\hline
\end{tabular}

Nos exemplos de (14) a (16), os predicados exak "ver", àwàxi "encontrar" e zuwàn "abraçar" recebem o prefixo $\{z e-\}$. Nesta circunstância, emerge a voz recíproca, já que os DPs sujeitos dessas construções correspondem a um conjunto de indivíduos, os quais praticam mutuamente a ação uns sobre os outros.

Vale ressaltar que o morfema recíproco $\{z e-\}$ em Tenetehára é análogo ao prefixo recíproco $\{j o-\}$ de outra língua da família Tupí-Guaraní, o Kamaiurá. Observe, a seguir, o exemplo do Kamaiura, retirado de Seki (2000, p. 284).

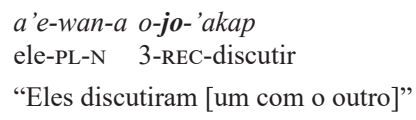

8 "Anaphors, such as reciprocals and reflexives, require antecedents that bind them. In this, their behavior is quite different from that of pronouns, which may having binding, but need not. Additionally, at least in English and a number of other languages, the antecedent of an anaphor must be local to the anaphor. In particular, we have [...] Condition $A$ of the binding theory, [namely:] An anaphor must be bound in a local domain" (CHOMSKY 1995, p. 95). 
No exemplo (17), vê-se que o argumento a'ewana "eles" é o DP sujeito que introduz no evento um conjunto de indivíduos que praticam a ação uns sobre os outros, o que é marcado por meio do morfema $\{j o-\}$, cuja acepção é de reciprocidade. Contudo, é interessante notar que, enquanto a língua Tenetehára possui apenas um morfema, cuja função é denotar a voz recíproca e reflexiva, o Kamaiurá dispõe de um morfema para cada voz, isto pode ser confirmado por meio da comparação entre o dado em (17) e o seguinte exemplo:

$\begin{array}{llll}\text { kunu'um-a } & \text { o-je-kytsi } & \text { kye'i-a } & \text { pupe } \\ \text { menino-N } & \text { 3-REFL-cortar } & \text { faca-N } & \text { INSTR }\end{array}$

"O menino se cortou com a faca" (SEKI, 2000, p. 279)

No exemplo em (18), o verbo transitivo kytsi "cortar" recebe o morfema reflexivo $\{j e-\}$, situação morfossintática em que emerge uma estrutura reflexiva, tendo em vista que o sujeito kunu'uma "menino" pratica e sofre a ação descrita pelo predicado verbal. Assim, fica evidente que, enquanto a língua Tenetehára se utiliza apenas de um morfema para cobrir as duas vozes, o Kamaiurá disponibiliza duas unidades gramaticais distintas, são elas: $\{j o-\}$ e $\{j e-\}$, conforme o seguinte quadro.

Quadro 1. Prefixos reflexivos e recíprocos

\begin{tabular}{|c|c|c|}
\hline Voz & Tenetehára & Kamaiurá \\
\hline Reflexiva & $\{z e-\}$ & $\{j e-\}$ \\
\hline Recíproca & $\{z e-\}$ & $\{j o-\}$ \\
\hline
\end{tabular}

Portanto, tendo em vista que o prefixo $\{z e-\}$ em Tenetehára acumula as funções de reflexividade e reciprocidade, diferentemente do que ocorre em Kamaiurá, é possível que construções com essa morfologia resultem em sentenças ambíguas, como é o caso, por exemplo, do dado em (19).

$$
\begin{aligned}
& \text { u-ze-(e)xak kwarer a'e wà } \\
& \text { 3-REFL/REC-ver menino } 3 \text { PL }
\end{aligned}
$$

Pode-se afirmar que a ambiguidade presente em (19) só é possível porque o prefixo $\{z e-\}$ possui a função de codificar as vozes reflexivas e recíprocas. Ambiguidades como essa não são esperadas na língua Kamaiurá, por exemplo, uma vez que esta língua dispõe de morfologias distintas para cada uma dessas duas vozes.

$\mathrm{Na}$ subseção seguinte, o intuito é tecer considerações acerca da voz anticausativa, com base, principalmente, nas intuições de Nedjalkov e Silnickij (1973). 


\subsection{Voz Anticausativa}

O objetivo desta subseção é apresentar argumentos, de acordo com Castro (2017), a favor da hipótese de que a voz anticausativa em Tenetehára também é codificada pelo morfema $\{z e-\}$, o qual está em uma possível relação de polissemia ${ }^{9}$ com a voz reflexiva e recíproca, como nos exemplos de (20) a (24) a seguir.

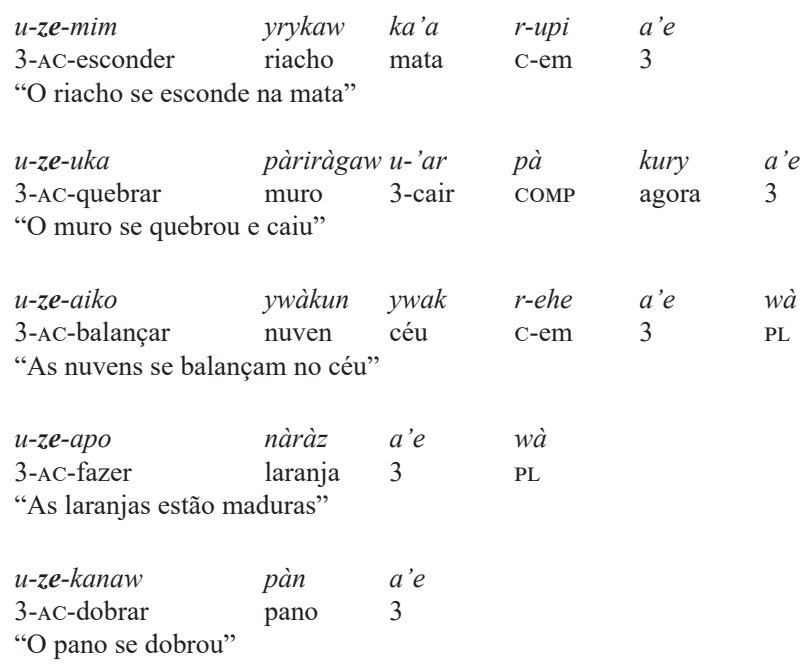

Nos exemplos de (20) a (24), nota-se que os verbos mim "esconder", $k a$ "quebrar", aiko "balançar", apo "fazer" e kanaw "dobrar" podem coocorrer com o prefixo $\{z e-\}$, a fim de codificar uma estrutura anticausativa, uma vez que não existem agentes nessas sentenças. Tudo indica que o prefixo $\{j e-\}$ em Kamaiurá também desempenha a função de anticausativo, conforme o seguinte exemplo, embora Seki (2000) o analise como morfema reflexivo.

$$
\begin{array}{lll}
\text { wyrapĩ-a } & \text { r-upi’a } & \text { o-je-ka } \\
\text { passarinho-N } & \text { REL-ovo } & \text { 3-REFL-quebrar } \\
\text { "O ovo de passarinho quebrou" } & \text { (SEKI, 2000, p. 300) }
\end{array}
$$

Em (25), o verbo transitivo $k a$ "quebrar" seleciona o sujeito wyrapĩa rupi'a "ovo do passarinho". Adicionalmente, o morfema $\{j e-\}$ sinaliza que as mesmas condições gramaticais responsáveis pelo acionamento do morfema $\{z e-\}$ nos dados de (20) a (24) também podem ser observadas no dado em (25). Mais especificamente, o predicado verbal transitivo tem sua valência diminuída e o único argumento nuclear desse verbo não tem papel temático de agente. Por essa razão, pode-se afirmar que de fato não há uma estrutura propriamente reflexiva em (25), mas sim uma construção anticausativa.

${ }^{9}$ De acordo com Câmara Jr. (1970, p. 27), o conceito gramatical de polissemia tem a ver com "a possibilidade de uma forma ter variações de sentido muito nítidas". 
Deve-se ressaltar que o termo voz anticausativa foi inicialmente proposto por Nedjalkov e Silnickij (1973, p. 7) da seguinte forma: "o membro não causativo de uma oposição, que deve ser formalmente marcado por meio de um afixo anticausativo, será denominado como anticausativo"10. Em síntese, ocorre voz anticausativa quando não há como recuperar o argumento externo causador ou um agente de causação na estrutura sintática de superfície. Essas construções como em (20) a (24) têm sido tratadas como as contrapartes intransitivas das sentenças causativas e receberam muitos nomes diferentes na literatura, anticausativas é uma dessas denominações. Além de Nedyalkov e Silnitsky (1973), o termo foi adotado por Siewierka (1984), Haspelmath (1987, 1990, 1993), Cennamo (1993, 1998), Michaelis (1998), Alexiadou et al. (2006), Schäfer (2008), KoontzGarboden $(2007,2009)$, entre muitos outros. Outros nomes utilizados para a mesma construção são: incoativos (LEVIN, 1993; FOLLI, 2002), decausativos (GENIUŠIENĖ, 1987; MEL'ČUK, 1993), espontâneos (SHIBATANI, 1985, KEMMER, 1993) e ergativos (ZRIBI-HERTZ, 1987).

Para exemplos na língua Tenetehára em que se pode notar o par causativo/ anticausativo, observe os seguintes dados:

\begin{tabular}{|c|c|c|c|}
\hline a. & $\begin{array}{l}\text { u-mim Mayr } \\
\text { 3-esconder Maíra } \\
\text { "O Maíra escondeu o o }\end{array}$ & $\begin{array}{l}\text { yryk-(h)awa'e } \\
\text { fluir-NOML } 3 \\
\text { riacho na mata" }\end{array}$ & \\
\hline b. & $\begin{array}{l}u \text {-ze-mim } \\
\text { 3-AC-esconder } \\
\text { "O riacho se escondel }\end{array}$ & $\begin{array}{l}\text { yryk-(h)awka'a } \\
\text { fluir-NOML mata } \\
\text { u na mata" }\end{array}$ & $\begin{array}{l}r \text {-upi } \\
\text { C-em }\end{array}$ \\
\hline a. & $\begin{array}{l}u \text {-ka awa } \\
\text { 3-quebrar homem } \\
\text { "O homem quebrou o }\end{array}$ & $\begin{array}{l}\text { pàriràg-(h)aw } \\
\text { cercar-NOML } \\
\text { muro" }\end{array}$ & $\begin{array}{l}a^{\prime} e \\
3\end{array}$ \\
\hline b. & $\begin{array}{l}u \text {-ze-uka } \\
\text { 3-AC-quebrar } \\
\text { "O muro se quebrou" }\end{array}$ & $\begin{array}{l}\text { pàriràg-(h)aw } \\
\text { cercar-NOML }\end{array}$ & $\begin{array}{l}a^{\prime} e \\
3\end{array}$ \\
\hline
\end{tabular}

Em (26a) e (27a), ocorrem os verbos transitivos mim "esconder" e $k a$ "quebrar", os quais selecionam como seus sujeitos Mayr "Maíra" e awa "homem", além dos objetos yrykaw "riacho" e pàriràgaw "muro", respectivamente. Já nos exemplos em (26b) e (27b), ocorre o apagamento dos argumentos Mayr "Maíra" e awa "homem", da estrutura argumental dos predicados verbais.

Mais especificamente, o morfema de voz anticausativa surge nos contextos em que (i) não existe um agente na sentença, (ii) o argumento interno passa a ocupar a posição sintática de sujeito e (iii) o antecedente que vincula o sujeito da sentença é um DP coindexado com este sujeito. Abaixo, fornecemos o Quadro 2 com os morfemas reflexivos, recíprocos e anticausativos em Tenetehára e em Kamaiurá.

10 "The non-causative member of an opposition which is formally marked by means of an anticausative affix will be said to be an anticausative" (NEDJALKOV; SILNICKIJ, 1973, p. 7). 
Quadro 2. Morfemas causativos, recíprocos e anticausativos

\begin{tabular}{|c|c|c|}
\hline Voz & Tenetehára & Kamaiurá \\
\hline Reflexivo & $\{z e-\}$ & $\{j e-\}$ \\
\hline Recíproco & $\{z e-\}$ & $\{j o-\}$ \\
\hline Anticausativo & $\{z e-\}$ & $\{j e-\}$ \\
\hline
\end{tabular}

Note que a língua Tenetehára se utiliza apenas do morfema $\{z e-\}$ para cobrir as três vozes, enquanto o Kamaiurá disponibiliza duas unidades gramaticais, a saber: $\{j e-\}$ para os reflexivos e anticausativos e $\{j o-\}$ para os recíprocos. Visando encontrar uma explicação para as ambiguidades produzidas pelo morfema $\{z e-\}$ em Tenetehára, como no exemplo em (19), apresentamos no Quadro 3 as seguintes propriedades gramaticais, a saber: agentividade, correfenciação e pluralidade.

Quadro 3. Morfologia de intransitivização e suas propriedades gramaticais

\begin{tabular}{|c|c|c|c|}
\hline Voz & Correferenciação & Agentividade & Pluralidade \\
\hline \multirow{2}{*}{ Reflexiva } & + & + & $+/-$ \\
\hline & \multicolumn{3}{|c|}{$z e-$} \\
\hline \multirow{2}{*}{ Recíproca } & + & + & + \\
\hline & \multicolumn{3}{|c|}{$z e-$} \\
\hline \multirow{2}{*}{ Anticausativa } & + & - & $+1-$ \\
\hline & \multicolumn{3}{|c|}{$z e-$} \\
\hline
\end{tabular}

Como foi visto, o prefixo $\{z e-\}$ tem a função de codificar as vozes reflexiva, recíproca e anticausativa. Devido a isso, em alguns contextos, as construções com o morfema $\{z e-\}$ podem inclusive resultar em sentenças ambíguas. Note que a voz anticausativa emerge quando o sujeito da sentença exibe propriedades não agentivas, ao passo que nas vozes reflexiva e recíproca o sujeito será necessariamente um agente. Contudo, quando não está totalmente clara a função semântica do sujeito quanto à agentividade, ambiguidades surgem como em (28). Assim, pode-se afirmar que a interpretação em (i) abaixo ocorre devido à função reflexiva do prefixo $\{z e-\}$, já a leitura em (ii) é possível tendo em vista sua função anticausativa.

$$
\begin{aligned}
& \text { u-ze-kixi awa takihe ø-pupe a'e } \\
& \text { 3-REL/AC-cortar homem faca C-com } 3 \\
& \text { (i) "O homem se cortou com a faca (intencionalmente)" } \\
& \text { (ii) "O homem se cortou com a faca (acidentalmente)" }
\end{aligned}
$$

Por outro lado, nota-se também que, quando o sujeito é agente e plural, é possível a ocorrência de ambiguidades entre as vozes reflexiva e recíproca, como em (29). Dessa maneira, pode-se constatar que a leitura (i) abaixo é possível 
devido à função reflexiva do prefixo $\{z e-\}$; contudo, a interpretação (ii) ocorre por causa de sua função recíproca.

$$
\begin{array}{llll}
\text { u-ze-(e)xak } & \text { kwarer } & a^{\prime} e & \text { wà } \\
\text { 3-REFL/REC-ver } & \text { menino } & 3 & \text { PL }
\end{array}
$$

(i) "Os meninos viram a si próprios (cada um se vendo na superfície da água, por exemplo)"

(ii) "Os meninos viram uns aos outros (se olhando reciprocamente)"

Na próxima seção, o intuito é evidenciar que morfemas causativos e reflexivos podem coocorrer em Tenetehára. Além do mais, as derivações são capazes de modificar a semântica da dinâmica das forças perceptíveis nos eventos.

\section{COOCORRÊNCIA DO MORFEMA REFLEXIVO $\{Z E-\}$ E DOS MORFEMAS CAUSATIVOS $\{M U-\}$ E $\{-K A R\}$}

Nesta seção, o objetivo é analisar, segundo Castro (2017), as propriedades morfossintáticas e semânticas dos morfemas causativos e do reflexivo nos contextos em que eles coocorrem. O exame minucioso de tais propriedades tem como intuito (i) verificar como se dá o mecanismo de retomada anafórica, (ii) verificar a ordem linear em que estes afixos ocorrem, (iii) verificar de que forma a semântica da dinâmica das forças perceptíveis nos eventos é sensível às derivações pertinentes e, por fim, (iv) investigar sobre qual argumento recai a dinâmica do impacto das forças no evento em um verbo intransitivo inativo, por exemplo. Veja os exemplos a seguir.

\begin{tabular}{|c|c|c|c|c|c|}
\hline a. & $\begin{array}{l}\text { i-puràg kuzàtài } \\
\text { 3-bonita menina } \\
\text { "A menina está bonita }\end{array}$ & $\begin{array}{l}a^{\prime} e \\
3 \\
\text { a" }\end{array}$ & & & \\
\hline b. & $\begin{array}{l}\text { u-mu-puràg } \\
\text { 3-CAUS-bonita } \\
\text { "A mulher embelezou }\end{array}$ & $\begin{array}{l}\text { kuzà } \\
\text { mulher } \\
\text { a menina" }\end{array}$ & $\begin{array}{l}\text { kuzàtài } \\
\text { menina }\end{array}$ & $\begin{array}{l}a^{\prime} e \\
3\end{array}$ & \\
\hline c. & $\begin{array}{l}\text { u-mu-puràg-kar } \\
\text { 3-CAUS-bonita-CAUS }\end{array}$ & $\begin{array}{l}\text { awa } \\
\text { homem }\end{array}$ & $\begin{array}{l}\text { kuzàtài } \\
\text { menina }\end{array}$ & $\begin{array}{l}\text { kuzà } \\
\text { mulher }\end{array}$ & $\begin{array}{l}\text { ø-pe } \\
\text { C-por }\end{array}$ \\
\hline
\end{tabular}

Os exemplos em (30) mostram que o verbo intransitivo inativo puràg "estar bonito" pode ser causativizado por meio do prefixo de causação direta $\{m u-\}$. O resultado é a formação do verbo transitivo causativo mu-puràg "embelezar", como pode ser visto em (30b). Pode-se observar ainda que o verbo transitivo causativo mu-puràg "embelezar" foi novamente causativizado por meio do morfema $\{-k a r\}$, conforme (30c). Este último processo resulta em uma causação semanticamente indireta. Em termos argumentais, o resultado é um predicado verbal que apresenta em sua grade temática três argumentos nucleares: o sujeito agente, o causee (agente-afetado) e o objeto afetado. Além do mais, esta sentença apresenta uma estrutura com três subeventos, conforme delineado em (31). 


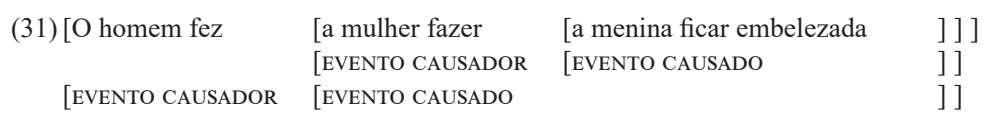

Pode-se afirmar que o subevento "a mulher fazer" é desencadeado pelo subevento "o homem fez", ao mesmo tempo em que desencadeia o subevento "a menina fica embelezada". Isso só é possível porque a sentença (30a) é submetida a dois processos consecutivos de causativização, o que é evidenciado pela realização simultânea dos causativos $\{m u-\}$ e $\{-k a r\}$. Ademais, o predicado duplamente causativizado mu-puràg-kar "fazer fazer embelezar", conforme (30c), pode ser submetido ao processo de reflexivização por meio do prefixo $\{z e-\}$, o resultado será a sentença em (32).

$\begin{array}{lllll}\text { u-ze-mu-puràg-kar } & \text { awa } & \text { kuzà } & \emptyset \text {-pe } & a^{\prime} \text { e } \\ \text { 3-REFL-CAUS-bonita-CAUS } & \text { homem } & \text { mulher } & \text { C-por } & 3 \\ \text { "O homem }{ }_{\mathrm{k}} \text { fez a mulher embelezá-lo }{ }_{\mathrm{k}} \text { " } & & & \end{array}$

O resultado semântico desta reflexivização é que o impacto do evento causado recai sobre o DP argumento externo agente pertencente à causação indireta, a saber: o DP sujeito awa "homem". Desta forma, os três subeventos podem ser vislumbrados da seguinte forma:

\begin{tabular}{|c|c|c|}
\hline [O homem hez & $\begin{array}{l}\text { [a mulher fazer } \\
\text { [EVENTO CAUSADOR }\end{array}$ & $\begin{array}{l}{\left[<\mathrm{o} \text { homem }>_{\mathrm{k}} \text { ficar embelezado }\right.} \\
\text { [EVENTO CAUSADO }\end{array}$ \\
\hline DOR & [EVENTO CAUSADO & \\
\hline
\end{tabular}

Alternativamente, o processo de reflexivização também pode ser anterior à causativização com o morfema causativo $\{-k a r\}$. Os dados abaixo trazem um contexto em que se mostram as várias etapas da derivação.
a. i-puràg kuzàtài a'e
3-bonita menina 3
"A menina está bonita"
b. u-mu-puràg kuzà kuzàtài a'e
3-CAUs-bonita mulher menina 3
"A mulher embelezou a menina"
c. u-ze-mu-puràg kuzà a'e
3-REFL-CAUS-bonita mulher ela
"A mulher se embelezou"

No exemplo (34c), o verbo transitivo causativo mu-puràg "embelezar" recebe o morfema $\{z e-\}$, o qual tem a função de reflexivizar essa predicação. $\mathrm{O}$ resultado é que o DP kuzà "mulher" é o sujeito agente sobre o qual também recai a ação verbal. Esta construção, por sua vez, pode ser novamente causativizada, conforme os exemplos em (35). 
a.

$\begin{array}{lccc}\text { u-mu-ze-mu-puràg } & \text { kuzà } & \text { kuzàtài a'e } \\ \text { 3-CAUS-REFL-CAUS-bonita } & \text { mulher menina } 3 \\ \text { "A mulher fez a menina se embelezar" (causação direta) }\end{array}$

b.

$\begin{array}{lllc}\text { u-mu-ze-mu-puràg-kar} & \text { kuzà } & \text { kuzàtài } & \text { a'e } \\ \text { 3-CAUS-REFL-CAUS-bonita-CAUS } & \text { mulher } & \text { menina } & 3 \\ \text { "A mulher fez a menina se embelezar" (causação indireta) }\end{array}$

Note que a predicação transitiva reflexivizada ze-mu-puràg "embelezarse", de (34c), é novamente causativizada por meio do prefixo $\{m u-\}$ em (35a), evolvendo o predicado à forma mu-ze-mu-puràg "fazer embelezar-se". Vale ressaltar que o morfema $\{m u$ - $\}$ tem a função de introduzir uma causação direta. Assim, a ação do DP kuzà "mulher" deve ter um impacto direto sobre o evento causado, o qual é introduzido por ze-mu-puràg "embelezar-se". Para o exemplo em (35b), por sua vez, após a formação do predicado mu-ze-mu-puràg "fazer embelezar-se", o complexo morfológico pode ainda receber o causativo indireto $\{-k a r\}$, gerando mu-ze-mu-puràg-kar "fazer embelezar-se". Nota-se que a causação indireta deve ser marcada pela dupla causativização quando o predicado for uma estrutura intransitiva (ou intransitivizada).

Portanto, na construção em (35b), vemos que a causativização indireta de verbo transitivo reflexivizado também é codificada pela ocorrência simultânea dos dois morfemas causativos. Ademais, podemos delinear, mais uma vez, os três subeventos desse exemplo conforme (36).

$\begin{array}{llll}{[\text { A mulher fez }} & {\left[\text { menina }_{\mathrm{k}} \text { fazer }\right.} & {\left[<\text { menina }_{\mathrm{k}} \text { ficar embelezada }\right.} & ]] \\ & {[\text { EVENTO CAUSADOR }} & \text { [EVENTO CAUSADO } & ] \\ \text { [EVENTO CAUSADOR } & {[\text { EVENTO CAUSADO }} & & ]]\end{array}$

De modo geral, note que há duas situações, a saber: (i) o morfema $\{m u$ - $\}$ indica a causação direta, como em (35a), e (ii) os morfemas $\{m u-\}$ e $\{-k a r\}$ assinalam a causação indireta, conforme o exemplo (35b).

A partir das análises realizadas, chega-se aos padrões de ordenação dos morfemas reflexivo, causativos e da raiz verbal. Esta distribuição revela não só o tipo semântico da causação, mas também sobre qual argumento recai a dinâmica do impacto das forças no evento, conforme os Quadros 4 e 5 a seguir. 
Quadro 4. Ordem linear dos afixos verbais (situação 1)

\begin{tabular}{|c|c|c|c|c|c|c|c|c|c|}
\hline \multirow{3}{*}{ 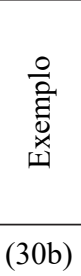 } & \multicolumn{4}{|c|}{ Ordem linear dos afixos } & \multicolumn{2}{|c|}{ Tipo de causação } & \multicolumn{3}{|c|}{$\begin{array}{l}\text { Argumento que recebe } \\
\text { o impacto no evento } \\
\text { introduzido pelo verbo }\end{array}$} \\
\hline & & & & & \multirow{2}{*}{$\begin{array}{c}\text { Direta } \\
\qquad \checkmark\end{array}$} & \multirow{2}{*}{$\begin{array}{c}\text { Indireta } \\
-\end{array}$} & \multirow{2}{*}{$\begin{array}{c}\text { Sujeito } \\
- \\
\end{array}$} & \multirow{2}{*}{$\begin{array}{c}\text { Objeto } \\
\text { direto } \\
\checkmark\end{array}$} & \multirow{2}{*}{$\begin{array}{l}\text { Objeto } \\
\text { Obliquo } \\
\text { não há }\end{array}$} \\
\hline & - & $\{m u-\}$ & $V_{\text {raiz }}$ & - & & & & & \\
\hline$(30 c)$ & - & $\{m u-\}$ & $V_{\text {raiz }}$ & $\{-k a r\}$ & - & $\checkmark$ & - & $\checkmark$ & - \\
\hline$(32)$ & $\{z e-\}$ & $\{m u-\}$ & $\bigvee_{\text {raiz }}$ & $\{-k a r\}$ & - & $\checkmark$ & $\checkmark$ & não há & - \\
\hline
\end{tabular}

Quadro 5. Ordem linear dos afixos verbais (situação 2)

\begin{tabular}{|c|c|c|c|c|c|c|c|c|c|c|}
\hline \multirow{3}{*}{ 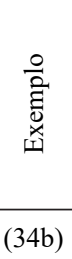 } & \multicolumn{5}{|c|}{ Ordem linear dos afixos } & \multicolumn{2}{|c|}{ Tipo de causação } & \multicolumn{3}{|c|}{$\begin{array}{l}\text { Argumento que recebe } \\
\text { o impacto no evento } \\
\text { introduzido pelo verbo }\end{array}$} \\
\hline & & & & & & \multirow{2}{*}{$\begin{array}{c}\text { Direta } \\
\checkmark \checkmark\end{array}$} & \multirow{2}{*}{$\begin{array}{c}\text { Indireta } \\
-\end{array}$} & \multirow{2}{*}{$\begin{array}{c}\text { Sujeito } \\
-\end{array}$} & \multirow{2}{*}{$\begin{array}{c}\text { Objeto } \\
\text { direto }\end{array}$} & \multirow{2}{*}{$\begin{array}{r}\text { Objeto } \\
\text { Obliquo } \\
\text { não há }\end{array}$} \\
\hline & - & - & $\{m u-\}$ & $V_{\text {raiz }}$ & - & & & & & \\
\hline$(34 c)$ & - & $\{z e-\}$ & $\{m u-\}$ & $V_{\text {raiz }}$ & - & $\checkmark$ & - & $\checkmark$ & não há & não há \\
\hline (35a) & $\{m u-\}$ & $\{z e-\}$ & $\{m u-\}$ & $V_{\text {raiz }}$ & - & $\checkmark$ & - & - & $\checkmark$ & não há \\
\hline$(35 b)$ & $\{m u-\}$ & $\{z e-\}$ & $\{m u-\}$ & $V_{\text {raiz }}$ & $\{-k a r\}$ & - & $\checkmark$ & - & $\checkmark$ & não há \\
\hline
\end{tabular}

Portanto, pode-se concluir que a ordem de coocorrência de $\{z e-\},\{m u-\}$ e $\{-k a r\}$ não é trivial em Tenetehára. A disposição e a ordem em que tais morfemas ocorrem produzem as construções apresentadas nos Quadros 4 e 5. Na próxima seção, encerramos o presente artigo com um resumo acerca dos assuntos abordados neste trabalho.

\section{CONSIDERAÇÕES FINAIS}

Neste artigo, tivemos como um dos objetivos oferecer uma análise descritiva das estruturas causativas na língua Tenetehára. Mostramos que esta língua apresenta dois morfemas causativos, a saber: (i) o morfema $\{m u-\}$, o qual causativiza verbos intransitivos ativos e inativos, introduzindo uma causação direta; e (ii) o morfema $\{-k a r\}$, cuja função é causativizar verbos transitivos, introduzindo uma causação indireta, conforme Camargos (2013). Adicionalmente, mostramos que em Tenetehára as construções que vêm marcadas por meio do morfema $\{z e-\}$ podem ser classificadas como reflexivas, recíprocas ou anticausativas, de acordo com Castro (2017). Em termos descritivos, este morfema afixa-se apenas a verbos transitivos (ou transitivizados). Além disso, analisamos as propriedades morfossintáticas e semânticas da coocorrência do prefixo reflexivo $\{z e-\}$ com os morfemas causativos $\{m u-\}$ e $\{-k a r\}$. Ademais, tivemos também como intuito 
verificar como se dá o mecanismo de retomada anafórica, considerando, para isso, a ordem linear em que estes afixos ocorrem. Finalmente, verificamos de que forma a semântica da dinâmica das forças perceptíveis nos eventos é sensível às derivações pertinentes e sobre qual argumento recai a dinâmica do impacto das forças em eventos verbais.

\section{REFERÊNCIAS}

ALEXIADOU, A.; ANAGNOSTOPOUlOU, E.; FLORIAN, S. The properties of anticausatives crosslinguistically. In.: FRASCARELLI, M. (Ed.). Phases of Interpretation. Berlin: Mouton de Gruyter, 2006. p. 187-211.

BENDOR-SAMUEL, D. Hierarchical structures in Guajajára. Oklahoma Norman: Summer Institute of Linguistics, 1972.

BOUDIN, M. H. Dicionário de Tupi Moderno: dialeto tembé-ténêtéhar do alto rio Gurupi. São Paulo: Conselho Estadual de Artes e Ciências Humanas, 1966.

CÂMARA JR, J. M. Estrutura da língua portuguesa. Petrópolis: Vozes, 1975.

CAMARGOS, Q. F.; CASTRO, R. C. Paralelismo entre DP e CP a partir das nominalizações na língua Tenetehára. Revista da ANPOLL, v. 32, n. 2, p. 393-434, 2013.

CAMARGOS, Q. F.; CASTRO, R. C. Morfemas causativos nas línguas indígenas brasileiras. Revista Sociodialeto do Grupo de Pesquisa e Estudos Sociolinguísticos e Dialetológicos da Universidade Estadual de Mato Grosso do Sul (GPESD - UEMS), v. 5, ed. 15, p. 198-218, 2015.

CAMARGOS, Q. F. Aplicativização, causativização e nominalização: uma análise unificada de estruturas argumentais em Tenetehára-Guajajára (Família Tupí-Guaraní). 2017. 256 f. Tese de Doutorado (Doutorado em Linguística). Belo Horizonte: Universidade Federal de Minas Gerais, 2017a.

CAMARGOS, Q. F. 2013. Estruturas Causativas em Tenetehára: uma abordagem minimalista. 2013. 255 f. Dissertação de Mestrado (Mestrado em Linguística). Belo Horizonte: Universidade Federal de Minas Gerais, 2013.

CAMARGOS, Q. F. Exploring agreement displacement from the Internal to the External Argument in the Tenetehára language (Tupí-Guaraní family). Revista Diadorim, v. 19, n. especial, p. 252$268,2017 b$

CARVAlHO, M. G. P. Sinais de morte ou vitalidade? Mudanças estruturais na lingua Tembé: contribuição ao estudo dos efeitos de contato linguístico na Amazônia Oriental. 2001. 120 f. Dissertação de Mestrado (Mestrado em Linguística). Belém: Universidade Federal do Pará, 2001.

CASTRO, R. C. Interface morfologia e sintaxe em Tenetehára. 2007. 90 f. Dissertação de Mestrado (Mestrado em Linguística). Belo Horizonte: Universidade Federal de Minas Gerais, 2007.

CASTRO, R. C. Morfossintaxe Tenetehára (Tupi-Guarani). 2017. 205 f. Tese de Doutorado (Doutorado em Linguística). Belo Horizonte: Universidade Federal de Minas Gerais, 2017. 
CENNAMO, M. The loss of the voice dimension between late Latin and early Romance. In.: SCHMID, M. et al. (Ed.). Historical Linguistics. Amsterdam: John Benjamins Publishing, 1998. p. 77-100.

CENNAMO, M. The Reanalysis of Reflexives: a Diachronic Perspective. Naples: Liguori, 1993.

CHOMSKY, N. The Minimalist Program. Cambridge: MIT Press, 1995.

COMRIE, B. Language universals and linguistic typology: syntax and morphology. Chicago: University of Chicago Press, 1981.

DUARTE, F. B.; CASTRO, R. C. Inergatividade, estrutura causativa e incorporação nominal em Tenetehára. In.: CABRAL, S. A. C.; RODRIGUES, A. D.; DUARTE, F. B. (Org.). Línguas e Culturas Tupí. Campinas: Curt Nimuendajú, 2010. p. 43-62.

DUARTE, F. B. Análise gramatical das orações da Lingua Tembé. 1997. 95 f. Dissertação de Mestrado (Mestrado em Linguística). Brasília: Universidade de Brasília, 1997.

DUARTE, F. B. Estudos de morfossintaxe Tenetehára. Belo Horizonte: Faculdade de Letras da Universidade Federal de Minas Gerais, 2007.

DUARTE, F. B. Manifestação de traços de tempo em D/NPS na língua Tenetehára. Revista de Estudos Linguísticos do Grupo de Estudos Linguísticos do Estado de São Paulo, v. 35, 2005. p. 773-881.

DUARTE, F. B. Ordem dos constituintes e movimento em Tembé: minimalismo e anti-simetria. 2003. 203 f. Tese de Doutorado (Doutorado em Linguística). Belo Horizonte: Universidade Federal de Minas Gerais, 2003.

DUARTE, F. B. The Split-S System and the source of the absolutive Case in Tenetehára. Revista LinguíStica, Rio de Janeiro, v. 13, n. 2, p. 317-367, 2017.

FREITAS, Maria Luisa de Andrade. Hierarquia de Pessoa em Avá Guarani: considerações a partir da morfologia distribuída. 2011. 182 f. Dissertação de Mestrado (Mestrado em Linguística). Campinas: Universidade Estadual de Campinas, 2011.

FOLLI, R. Constructing telicity in English and Italian. Unpublished doctoral dissertation, University of Oxford, 2002.

GENIUS̆IENĖ, E. The typology of reflexives. Berlin/New York/Amasterdam: Mouton de Gruyter, 1987.

HARRISON, C. The interplay of causative and desiderative in Guajajara. Revista dos Cursos de PósGraduação em Letras, Belém, n. 4, 1995.

HASPELMATH, M. More on the typology of inchoative/causative verb alternations. In.: COMRIE, B.; POLINSKY, M. (Ed.). Causatives and transitivity. Amsterdam: John Benjamins Publishing, 1993. p 87-120.

HASPELMATH, M. The grammatilization of passive morphology. Studies in Language, v. 14, n. 1, 1990 , p. $25-71$.

HASPELMATH, M. Transitivity alternations of the anticausative type. Arbeitspapiere des Instituts für Sprachwissenschaft, Cologne, n. 4, 1987. 
KEMMER, S. The Middle Voice. Typological Studies in Language, v. 23. Amsterdam/ Philadelphia: John Benjamins Publishing, 1993.

KOONTZ-GARBODEN, A. Anticausativization. Natural Language and Linguistic Theory, n. 27, p. 77-138, 2009.

KOONTZ-GARBODEN, A. Aspectual coercion and the typology of change of state predicates. Journal of Linguistics, n. 43, p. 115-152, 2007.

LEITE, Y. As construções causativas em Tapirapé. Revista Latinoamericana de Estudios Etnolingüísticos, n. 3, p. 73-86, 1994.

LEMOS BARBOSA, A. Curso de Tupi Antigo: Gramática, Exercícios, Textos. Rio de Janeiro: Livraria São José, 1956.

LEVIN, B. English Verb Class and Alternations: A Preliminary Investigation. Chicago: University of Chicago Press, 1993.

MARTINS, Marci Fileti. Descrição e análise de aspectos da gramática do Guarani Mbya. 2003. 220 f. Tese de Doutorado (Doutorado em Linguística). Campinas: Universidade do Estado de Campinas, 2003.

MICHAELIS, L. Aspectual Grammar and Past-Time Reference. London: Routledge, 1998.

NEDJALKOV, V. P.; SILNICKIJ, G. The Typology of Morphological and Lexical Causatives. In.: KIEFER, F. Trends in Soviet Theoretical Linguistics. Doordrecht: Reidel, 1973. p. 1-32.

RODRIGUES, A. D. Morfologia do Verbo Tupi. Revista Letras, v. 1, p. 121-152, 1953.

SCHÄFER F. The Syntax of (Anti-)Causatives. Amsterdam: John Benjamins Publishing, 2008.

SEKI, L. Gramática do Kamaiurá: Língua Tupí-Guarani do Alto Xingu. Campinas: Editora da UNICAMP, 2000.

SHIBATANI, M. Passives and related constructions: a prototype analysis. Language, v. 61, n. 4, p. 821-848, 1985.

SIEWIERKA, A. The Passive: A Comparative Linguistic Analysis. London: Croom Helm, 1984.

SILVA, T. F. História da língua Tenetehára: contribuições aos estudos histórico-comparativos sobre a diversificação da família Tupí-Guaraní do tronco Tupí. 2010. 1145 f. Tese de Doutorado (Doutorado em Linguística). Brasília: Universidade de Brasília, 2010.

SMITH, C. Jesperson's 'move and change' class and causative verbs in English. In.: ALI JAZAYERY, M. et al. (Ed.). Linguistic and Literary Studies in Honor of Archibald A. Hill, Vol. 2. Amsterdam: John Benjamins Publishing, 1970. p. 101-109.

WHALEY, L. Introduction to typology: the unity and diversity of language. London: Sage, 1977.

ZRIBI-HERTZ, A. L'Ergativité réflexive en français moderne, In: Le français moderne, v. 55, p. 2354, 1987. 